\title{
Tendências do Fitness em Portugal para 2021
}

\section{Fitness Trends in Portugal for 2021}

\section{Tendencias de Fitness en Portugal para 2021}

\author{
Franco, $S^{1,2}$, Santos-Rocha, $\mathrm{R}^{1,3}$, Ramalho, $\mathrm{F}^{1,3}$, Simões, $\mathrm{V}^{1,2}$, Vieira, ${ }^{1,2}$, Ramos, $\mathrm{L}^{1,2}$. \\ ${ }^{1}$ Escola Superior de Desporto de Rio Maior - Instituto Politécnico de Santarém, ${ }^{2}$ Centro de Investigação \\ em Qualidade de Vida (CIEQV); ${ }^{3}$ Centro Interdisciplinar de Estudo da Performance Humana (CIPER)
}

\section{RESUMO}

O American College of Sports Medicine (ACSM) publica anualmente um estudo com as tendências mundiais do fitness para o ano seguinte. O presente estudo reproduziu a metodologia do estudo das tendências do ACSM e caracterizou as tendências do fitness em Portugal para 2021 segundo os profissionais, os estudantes e os praticantes do setor, confrontando os resultados com os estudos a nível mundial, europeu e espanhol. Foram também comparadas as tendências entre os praticantes e os profissionais/estudantes, e nestes entre géneros, exercer ou não funções enquanto profissional e possuir o título de Técnico de Exercício Físico (TEF), Diretor Técnico (DT) ou não possuir título. Responderam a um questionário online, construído para o efeito, 165 profissionais, 135 estudantes e 85 praticantes.

Como resultado, foram identificadas as principais tendências para o fitness em Portugal para 2021, nos diferentes grupos da amostra. Portugal tende a ir mais ao encontro das tendências europeias, do que das mundiais. $\mathrm{Na}$ comparação entre os profissionais/estudantes e os praticantes existiram diferenças em 4 das 42 tendências, entre géneros em 20, entre profissionais que exerciam ou não funções em 7, e entre títulos de TEF, DT ou sem título em 9. Em conclusão, não obstante a variabilidade de opiniões entre grupos de sujeitos, poder-se-á dizer que, consensualmente, as principais tendências do fitness em Portugal para 2021 são: licenças (títulos) para profissionais de fitness, empregar profissionais de fitness certificados, exercício para perda de peso, estilo de vida saudável e mudança comportamental, atividades outdoor e treino com o peso corporal.

Palabras chave: Portugal, Tendências, Fitness

\begin{abstract}
The American College of Sports Medicine (ACSM) publishes an annual study of world fitness trends for the following year. The present study reproduced the methodology of ACSM trends study and characterized the fitness trends in Portugal for 2021 according to professionals, students and clients in the sector, confronting the results with studies at a worldwide, European and Spanish level. The trends between clients and professionals/students were also
\end{abstract}




\section{Fitness em Portugal para 2021}

compared, and in these, between genders, whether or not to perform functions as a professional and to have the title of Physical Exercise Technician (TEF), Technical Director (DT) or not to have a title. 165 professionals, 135 students and 85 clients answered to an online questionnaire, built for this purpose.

As a result, the main trends for fitness in Portugal for 2021 were identified, in the different sample groups. Portugal tends to be more in line with European trends than worldwide ones. In the comparison between professionals/students and clients, there were differences in 4 out of 42 trends, between genders in 20, between professionals who performed functions with those who did not in 7, and between titles of TEF, DT or untitled in 9. In conclusion, despite the variability of opinions between groups of subjects, it can be said that, by consensus, the main fitness trends in Portugal for 2021 are: licenses (titles) for fitness professionals, employing certified fitness professionals, exercise for weight loss, healthy lifestyle and behavioral change, outdoor activities and bodyweight training.

Keywords: Portugal, Trends, Fitness

\section{RESUMEN}

El Colegio Americano de Medicina Deportiva (ACSM) publica anualmente un estudio que identifica las tendencias mundiales de fitness para el año siguiente. El estudio presente reproduce la metodología del estudio de las tendencias del ACSM y caracterizó las tendencias del fitness en Portugal para 2021 según profesionales, estudiantes y practicantes del sector, confrontando los resultados con estudios a nivel mundial, europeo y español. También se compararon las tendencias entre practicantes y profesionales/estudiantes, y en esta entre géneros, ejercer o no funciones como profesional y tener el título de Técnico en Ejercicio Físico (TEF), Director Técnico (DT) o no tener título. Respondieron a un cuestionario online, diseñado para tal fin, 165 profesionales, 135 estudiantes y 85 practicantes.

Como resultado, se identificaron las principales tendencias del fitness en Portugal para 2021, en los diferentes grupos de la muestra. Portugal tiende a estar más en línea con las tendencias europeas que con las mundiales. En la comparación entre profesionales/estudiantes y practicantes, hubo diferencias en 4 de 42 tendencias, entre géneros en 20, entre profesionales que ejercían funciones o no en 7, y entre títulos de TEF, DT o sin título en 9. En conclusión, a pesar de la variabilidad de opiniones entre grupos de sujetos, se puede decir que, por consenso, las principales tendencias del fitness en Portugal para 2021 son: licencias (títulos) para profesionales de fitness, emplear profesionales de fitness certificados, ejercicio para bajar de peso, estilo de vida saludable y cambio de comportamiento, actividades outdoor y entrenamiento con el peso corporal.

Palavras chave: Portugal, Tendencias, Fitness

\section{INTRODUCÃO}

Atualmente é amplamente reconhecida pela comunidade científica a importância do exercício físico em diversas variáveis associadas à saúde dos cidadãos (Siddiqui, Nessa \& Hossain, 2010), bem como à diminuição da mortalidade (Ekulund et al., 2016) e à relação positiva que existe entre a prática de atividade física, qualidade de vida e bem-estar (Marquez et al., 2020).

A indústria do fitness, que proporciona a prática de exercício físico de diversas modalidades em ginásios/health clubs ou espaços similares, tem crescido substancialmente ao longo das últimas quatro décadas, atingindo em 2019, antes da pandemia provocada pela doença COVID-19, mais de 184 milhões de praticantes em aproximadamente $210 \mathrm{mil}$ instalações de fitness segundo a Internacional Health, Racquet \& Sportsclub Association (IHRSA, 2020). $\mathrm{O}$ último Eurobarómetro da atividade física, realizado em 2018 , refere que mais de $68 \%$ dos portugueses não realiza qualquer tipo de exercício/desporto e 6\% realiza-o raramente (TNS Opinion \& Social, 2018). Apesar desses resultados, o mesmo barómetro refere que, das pessoas que praticam exercício físico, a maioria o realiza em instalações de fitness, o que acentua ainda mais a importância que este setor possui no panorama geral dos serviços de oferta desportiva em Portugal, particularmente em adultos. Os números relacionados com o setor do fitness em Portugal têm, 


\section{Franco et al.}

à semelhança do que acontece um pouco por todo o mundo, crescido substancialmente. A Associação de Ginásios e Academias de Portugal (AGAP) tem realizado, ao longo dos últimos anos, um barómetro com os principais indicadores associados ao setor. Relativamente ao ano de 2019 existiam em Portugal cerca de 1100 ginásios, aproximadamente mais 100 do que no ano anterior. Em relação ao número de praticantes de atividades de fitness estes subiram de 592834, relativos ao ano de 2018, para 688210 em 2019, resultando numa taxa de penetração (percentagem de pessoas que praticam atividades de fitness face ao número de portugueses) de $6,7 \%$. A faturação global (sem IVA) do mercado do fitness atingiu em 2019 aproximadamente 290 milhões de euros, aumentando também relativamente ao ano anterior (AGAP, 2019, 2020). Já em relação ao número de profissionais do setor, este era, em 2019, de 12086 profissionais de fitness (PF) (AGAP, 2020), sendo que legalmente em Portugal podem exercer funções, nos ginásios/health clubs, enquanto PF os portadores do título de Diretor Técnico (DT) e Técnico de Exercício Físico (TEF) (Lei n. ${ }^{\circ}$ 39/2012 de 28 de agosto). Legalmente, para além das funções do TEF, o DT tem ainda outras funções, nomeadamente as relacionadas com a coordenação e supervisão da avaliação e prescrição, da atividade dos TEF, dos serviços, programas e atividades desportivas do ginásio/health club. Alguns instrumentos de análise da intervenção dos TEF têm sido adaptados ao contexto do fitness, apoiando a supervisão dos DTs (Alves et al., 2015; Dias et al., 2020; Franco et al., 2008; Luís et al., 2021).

Várias entidades têm contribuído, ao longo de décadas, para o crescimento e credibilidade do setor, sendo que o American College of Sports Medicine (ACSM) é inequivocamente uma delas. Para além de ser uma das entidades mundiais mais relevante em questões relacionadas com a avaliação e prescrição do exercício físico, possuindo diversos manuais com diretrizes específicas para esse efeito (ACSM, 2021), esta entidade tem elaborado anualmente, desde 2007, um estudo acerca das tendências do fitness mundiais (Thompson, 2006, 2007, 2008, 2009, 2010, 2011, 2012, 2013, 2014, 2015, 2016, 2017, 2018, 2019), contribuindo para ajudar o setor do fitness a tomar algumas decisões para o seu crescimento e desenvolvimento futuro, nomeadamente: profissionais de fitness, formadores, dirigentes de ginásios, empresas de materiais ou entidades formadoras. As tendências têm a capacidade de ganhar dinâmica e criar impacto social a longo prazo, podendo manifestar-se nas atitudes, valores e comportamentos do seu público-alvo, não obstante a localização geográfica e influências culturais associadas (ClubIntel, 2018). No ano de 2019, para além das tendências mundiais para 2020 (Thompson, 2019) foram também publicadas pelo ACSM quais seriam as tendências para a América do Norte, Ásia, Europa e América do Sul, bem como realizada a comparação entre as mesmas (Kercher, Feíto \& Yates, 2019). Relativamente a 2021, a mesma entidade confrontou os resultados obtidos na Austrália, Brasil, China, Europa, México, Espanha e Estados Unidos da América (Kercher et al., 2020), para além do estudo habitual do ACSM acerca das tendências mundiais, após o aparecimento da pandemia provocada pela doença COVID-19 (Thompson, 2020). Todos estes estudos pretendem conhecer as tendências do fitness através da opinião de vários intervenientes do setor de fitness e saúde, sendo que da amostra fizeram parte profissionais que intervêm diretamente com os praticantes de fitness (designadamente TEFs de aulas de grupo, sala de exercício, treino personalizado, fisiologistas do exercício), proprietários e gestores de ginásios, coordenadores de fitness, mas também estudantes da área do desporto/fitness (quer seja do ensino superior ou técnico) e profissionais de saúde ligados ao exercício (como médicos de medicina desportiva, fisioterapeutas, entre outros).

Considerando o possível impacto social das tendências, em termos de atitudes, valores e comportamentos do seu público-alvo, considerando a sua especificidade em termos geográficos e culturais (ClubIntel, 2018; Kercher et al., 2020), importa conhecer esta informação relativamente a Portugal. Não foi encontrado nenhum estudo acerca das tendências do fitness, especificamente em Portugal. Deste modo, o presente estudo pretende, como primeiro objetivo, caracterizar as tendências do fitness em Portugal para 2021 na mesma perspetiva que o ACSM, nomeadamente recolhendo a opinião do mesmo tipo de profissionais do setor e estudantes. São também expostos e discutidos os resultados obtidos em Portugal das tendências do fitness para $2021 \mathrm{em}$ confrontação com os resultados dos estudos desenvolvidos na Europa (Kercher et al., 2020), Espanha (Veiga, Valcarce-Torrete \& Cámara, 2021) e o estudo mundial das tendências do ACSM (Thompson, 2020). Porque os praticantes das 


\section{Fitness em Portugal para 2021}

atividades de fitness são os consumidores dos serviços de fitness, este estudo pretende também caracterizar as tendências do fitness em Portugal para 2021 segundo os praticantes de atividades de fitness sendo também realizada uma comparação acerca das tendências do fitness em Portugal para 2021 entre os praticantes e o referido grupo de profissionais/estudantes.

Ainda relativamente aos profissionais/estudantes do setor do fitness em Portugal, foram efetuadas algumas comparações acerca das tendências, nomeadamente entre géneros (masculino e feminino), entre possuir o título de TEF, DT ou não possuir título (sendo que aqui se incluem os estudantes e profissionais de saúde ligados ao exercício), e também entre pessoas que exerciam ou não funções enquanto profissionais de fitness no momento da recolha. Estas variáveis e grupos da amostra têm sido utilizados em outros estudos na área do fitness (Franco et al., 2013; Ramos et al., 2021).

Todos estes objetivos levarão a um maior conhecimento do setor do fitness, viabilizando que as instalações e os profissionais que fornecem serviços de fitness possam adaptar a sua oferta, contribuindo para a adesão e fidelização dos clientes, promovendo assim a prática de exercício e a melhoria da qualidade de vida dos cidadãos.

\section{MATERIAL E MÉTODOS}

\section{Amostra}

Participou neste estudo uma amostra de 300 pessoas do setor do fitness e saúde, com características semelhantes às utilizadas nos estudos acerca das tendências do fitness mundiais publicados pelo ACSM (Thompson, 2006, 2007, 2008, 2009, 2010, 2011, 2012, 2013, 2014, 2015, 2016, 2017, 2018, 2019). Esta amostra incluiu 165 profissionais do setor, nomeadamente os que intervêm diretamente com os praticantes de fitness (TEFs de aulas de grupo, sala de exercício, treino personalizado, fisiologistas do exercício), proprietários e gestores de ginásios, coordenadores de fitness, profissionais de saúde ligados ao exercício (como médicos de medicina desportiva, fisioterapeutas, etc.), assim como 135 estudantes da área do desporto/fitness (do ensino superior e do ensino técnico). Para além do que é habitual ser utilizado no ACSM, no presente estudo foi também utilizada uma amostra de 85 praticantes de atividades de fitness (caracterização na tabela 2).
Tabela 1 - Caracterização dos profissionais e estudantes do setor $(n=300)$.

\begin{tabular}{ll}
\hline Variáveis & \\
\hline Género & $(\%)$ \\
Feminino & 40.3 \\
Masculino & 59.7 \\
Exerce funções enquanto PF & $(\%)$ \\
Sim & 43.3 \\
Não & 36.4 \\
Não se aplica & 20.3 \\
Título enquanto profissional & $(\%)$ \\
TEF & 25.1 \\
DT & 26.8 \\
Sem título & 48.1 \\
Idade & $($ Anos $)$ \\
Média \pm Desvio Padrão & $26.8 \pm 9.3$ \\
\hline
\end{tabular}

Tabela 2 - Caracterização dos praticantes $(n=85)$.

\begin{tabular}{ll}
\hline Variáveis & $(\%)$ \\
\hline Género & 64.7 \\
$\quad$ Feminino & 28.2 \\
Masculino & 7.1 \\
Não respondeu & $($ Anos) \\
Idade & $36.1 \pm 10.9$ \\
$\quad$ Média \pm Desvio Padrão & $($ Anos) \\
Experiência enquanto praticante de & $11.4 \pm 10.2$ \\
atividades fitness & \\
$\quad$ Média \pm Desvio Padrão & \\
\hline
\end{tabular}

\section{Instrumento e procedimentos}

Relativamente ao instrumento, começou-se por traduzir as tendências do fitness utilizadas no questionário do ACSM para a Europa no ano de 2020 (Batrakoulis, 2019) e verificar se existiam outras tendências que se justificasse incluir no questionário, tal como realizado em Espanha (Veiga, ValcarceTorrete \& Cámara, 2021). Para tal, foram consultados seis especialistas na área do fitness em Portugal, com domínio da língua inglesa e portuguesa, os quais, para além das 41 tendências referidas no questionário europeu, sugeriram incluir a tendência Crosstraining (treino funcional das capacidades físicas, constantemente variado/alta intensidade, incluindo exercícios gímnicos, levantamento de pesos e arremessos; o programa mais conhecido é o $\mathrm{CrossFit}^{\circledR}$ ), por considerarem que é uma atividade bastante praticada no país e que tem vindo a crescer 


\section{Franco et al.}

nos últimos anos. Esta tendência já tinha sido identificada anteriormente pelo ACSM, apesar de atualmente não fazer parte da lista de tendências identificadas, quer mundialmente quer a nível europeu. Após a tradução e introdução da tendência Crosstraining foram desenvolvidos dois questionários.

O primeiro questionário foi dirigido aos profissionais/estudantes do setor do fitness e saúde (com uma amostra de tipos de sujeitos semelhante aos utilizados no estudo das tendências do ACSM). Para além das tendências, este questionário possuía também questões relacionadas com a caracterização sociodemográfica dos sujeitos, bem como relativas à sua intervenção no setor do fitness.

O segundo questionário foi dirigido aos praticantes de atividades de fitness e, para além das 42 tendências do fitness para 2021 (colocadas da mesma forma do que no questionário dos profissionais e estudantes) foram também inseridas questões de caracterização sociodemográfica, bem como da experiência que tinham enquanto praticantes de atividades de fitness. Em ambos os questionários, para cada uma das 42 tendências para o ano de 2021 em Portugal, foi utilizada uma escala Likert de 10 níveis, sendo 1 menor tendência e 10 - maior tendência.

Todos os questionários foram colocados na plataforma online SurveyMonkey, aos quais os respondentes tinham acesso através de um link, sendo que a sua aplicação foi realizada já após o início da pandemia causada pela doença COVID-19, entre maio e outubro de 2020. Para a divulgação do questionário dos profissionais foram contactadas universidades/politécnicos em Portugal com licenciaturas na área das ciências do desporto, exercício e saúde, condição física e saúde e similares, escolas de formação do ensino técnico do fitness em Portugal (que possuíssem cursos de especialização tecnológica (CET) de TEF), bem como associações do setor do fitness em Portugal, nomeadamente a Associação de Ginásios e Academias de Portugal (AGAP/Portugal Ativo), a Associação Portuguesa dos Fisiologistas do Exercício (APFE), a Associação Portuguesa de Técnicos de Exercício Físico (APTEF) e a União Portuguesa dos Diretores e Técnicos de Exercício Físico (UPDTEF) bem como foi realizada a divulgação do estudo nas redes sociais. A divulgação do questionário dos praticantes foi realizada através da difusão nas redes sociais por parte dos autores do estudo, bem como através de ginásios/health clubs que o propagaram pelos seus clientes. Existiu alguma dificuldade na divulgação do questionário por parte dos ginásios/health clubs, derivada da situação de pandemia provocada pela doença COVID-19. Quando se iniciou a recolha de dados os ginásios/health clubs ainda tinham os seus espaços físicos encerrados, embora pudessem funcionar online e em outdoor com grupos reduzidos, pelo que toda a comunicação que fizessem chegar aos sócios era extremamente sensível e muitas destas organizações acabaram por não o fazer. Em parte, este facto pode explicar a baixa taxa de respostas que obtivemos de praticantes de atividades de fitness.

\section{Análise Estatística}

Para caracterizar as tendências de fitness em Portugal para 2021 (nos profissionais/estudantes e nos praticantes) foi realizada a estatística descritiva de todas as tendências, nomeadamente a média $(M)$ e o desvio padrão $(D P)$. Nas comparações com dois grupos (género masculino e feminino; exercer ou não funções enquanto profissional de fitness; profissionais/estudantes e praticantes) foi utilizado o teste $t$, e nas comparações com três grupos de profissionais/estudantes (TEF, DT e sem título) foi utilizada a técnica estatística ANOVA complementada com um teste post hoc de Tukey (se as variâncias fossem homogéneas de acordo com o teste de Levene) ou um teste post hoc Games-Howell (se as variâncias não assumissem homogeneidade) (Ho, 2014; Pestana \& Gageiro, 2014).

\section{RESULTADOS}

Na tabela 3 encontram-se os resultados das 20 primeiras tendências do fitness para Portugal em 2021, relativamente aos profissionais e estudantes, bem como aos praticantes, sendo estes resultados de Portugal confrontados com os obtidos no estudo das tendências do fitness mundiais para 2021 (Thompson, 2020), os resultados das tendências Europeias para 2021 (Kercher et al., 2020) e o estudo realizado acerca das tendências do fitness em Espanha para 2021 (Veiga, Valcarce-Torrete \& Cámara, 2021), os quais se encontram organizados por ordem decrescente de pontuação. De realçar que a tendência "Licenças (títulos) para profissionais de fitness" e "Empregar profissionais de fitness certificados", encontra-se no top 3 de Portugal, tanto para os profissionais/estudantes como para os praticantes. 


\section{Fitness em Portugal para 2021}

$\mathrm{Na}$ tabela 4 são apresentados os resultados da caracterização e comparação das tendências entre os profissionais/estudantes do setor do fitness e saúde e os praticantes de fitness. Verificou-se que existem diferenças significativas apenas em 4 das 42 tendências, nomeadamente "Exercícios baseados na dança", "Fitness pré e pós-parto" e "Treino com electroestimulação", com maior média nos praticantes, e "Treino personalizado", com maior média nos profissionais/estudantes.

Quando caracterizadas e comparadas as tendências dos profissionais/estudantes do setor do fitness em relação ao género, foram identificadas diferenças significativas em 20 das 42 tendências (tabela 5), designadamente: "Acompanhamento de treino online", "Aparelhos de mobilidade/miofasciais", "Aulas de grupo", "Crosstraining", "Empregar profissionais de fitness certificados", "Exercícios baseados na dança", "Exercício como medicina", "Fitness pré e pós-parto", "Ginásios/health clubs low cost", "Licenças (títulos) para profissionais de fitness", "Medição de resultados", "Movimento corpo e mente", "Pilates", "Tecnologia wearable", "Treino com electroestimulação", "Treino do core", "Treino em circuito", "Treino intervalado de alta intensidade", "Treino virtual" e "Yoga". Realça-se que em todas as tendências onde foram verificadas diferenças significativas o género feminino apresentou valores superiores.

$\mathrm{Na}$ caracterização e comparação entre os profissionais de fitness (PF) que estavam a exercer funções (TEFs e DTs) com os que não estavam a exercer (tabela 6), nomeadamente os com título TEF, DT, gestores e coordenadores que não estavam a trabalhar na área, os estudantes e os profissionais de saúde relacionados com o exercício, foram encontradas diferenças em 7 das 42 tendências, nomeadamente: "Aparelhos de mobilidade/miofasciais", "Boxe, kickboxing, ou atividades relacionadas com artes marciais", "Desenvolvimento da juventude a longo prazo (desenvolvimento atlético)", "Hidroginástica", "Treino com electroestimulação", "Treino do core" e "Treino em circuito". Em todas essas diferenças significativas os profissionais que não estavam a exercer funções apresentaram valores superiores.

Em relação à caracterização e às diferenças existentes entre os profissionais com título de TEF, DT ou sem título profissional, nomeadamente alguns proprietários e gestores de fitness, os estudantes e os profissionais de saúde relacionados com o exercício (tabela 7), foram encontradas diferenças significativas em 9 das 42 tendências, designadamente: "Aparelhos de mobilidade/miofasciais", "Boxe, kickboxing, ou atividades relacionadas com artes marciais", "Clubes de caminhadas/corrida/ciclismo", "Desenvolvimento da juventude a longo prazo (desenvolvimento atlético)", "Medição de resultados", "Treino com electroestimulação", "Treino do core", "Treino em circuito" e "Treino funcional". Estas diferenças encontraram-se maioritariamente entre os DT e os sem título.

\section{DISCUSSSÃO}

O presente estudo pretendeu contribuir para o conhecimento do setor do fitness, nomeadamente as tendências para este setor em Portugal para 2021, segundo diferentes intervenientes.

Em relação aos resultados obtidos acerca das tendências do fitness para 2021 em Portugal, na opinião dos profissionais/estudantes do setor pode referir-se que as primeiras duas se relacionam com a preocupação em relação aos profissionais que trabalham nesta área, nomeadamente que estes estejam qualificados para esse efeito e que as entidades contratem profissionais certificados. A formação dos profissionais é cada vez mais valorizada sendo considerada por vários autores como essencial para a prestação de um bom serviço ao cliente (Antunes, 2003; Batista et al., 2008; Lloyd, 2008; Ramos et al., 2015) o que, de certa forma, pode justificar a importância lhes é dada neste estudo. O treino personalizado obteve o $3 .^{\circ}$ lugar na lista das tendências, o que pode ser explicado pelo elevado número de ginásios/health clubs que oferece este serviço ao cliente, sendo que segundo dados do Barómetro do Fitness em Portugal, da AGAP (2018), este serviço representou a $2 .^{a}$ fonte de receitas de ginásios/health clubs, logo a seguir às mensalidades dos clientes. As tendências relacionadas com o exercício para perda de peso $\left(4 .^{\circ}\right)$, estilo de vida saudável e mudança comportamental $\left(5 .^{\circ}\right)$ e treino de saúde/bem-estar $\left(8 .^{\circ}\right)$ assumem também particular importância para 2021, sendo que o facto de Portugal possuir, no ano de 2019, uma taxa de obesidade de mais de metade da população adulta (Instituto Nacional de Estatística (INE), 2019) pode contribuir para que os profissionais valorizem este tipo de tendências. 
Tabela 3 - Tendências do fitness, para 2021, em Portugal, nos profissionais/estudantes e nos praticantes, a nível mundial, a nível europeu e em Espanha.

\begin{tabular}{|c|c|c|c|c|c|}
\hline & $\begin{array}{c}\text { Tendências do Fitness em } \\
\text { Portugal para } 2021 \\
\text { Profissionais/estudantes } \\
\text { (presente estudo) }\end{array}$ & $\begin{array}{c}\text { Tendências do Fitness em } \\
\text { Portugal para } 2021 \\
\text { Praticantes } \\
\text { (presente estudo) }\end{array}$ & $\begin{array}{l}\text { Tendências Mundiais do } \\
\text { Fitness para 2021 } \\
\text { (Thompson, 2020) }\end{array}$ & $\begin{array}{c}\text { Tendências do Fitness na Europa } \\
\text { para } 2021 \\
\text { (Kercher et al., 2020) }\end{array}$ & $\begin{array}{c}\text { Tendências do Fitness em } \\
\text { Espanha para } 2021 \\
\text { (Veiga, Valcarce-Torrete \& } \\
\text { Cámara, 2021) }\end{array}$ \\
\hline 1 & Licenças (títulos) para PF & Empregar PF certificados & Treino online & PT & Exercício para perda de peso \\
\hline 2 & Empregar PF certificados & $\begin{array}{l}\text { Exercício para perda de } \\
\text { peso }\end{array}$ & Tecnologia wearable & HIIT & Empregar PFcertificados \\
\hline 3 & PT & Licenças (títulos) para PF & Treino com o peso corporal & Treino com electroestimulação & PT \\
\hline 4 & Exercício para perda de peso & $\begin{array}{l}\text { Estilo de vida saudável e } \\
\text { mudança comportamental }\end{array}$ & Atividades outdoor & Exercício para perda de peso & PT para pequenos grupos \\
\hline 5 & $\begin{array}{l}\text { Estilo de vida saudável e } \\
\text { mudança comportamental }\end{array}$ & Atividades outdoor & HIIT & Treino funcional & Treino funcional \\
\hline 6 & Atividades outdoor & HIIT & Treino virtual & Treino com o peso corporal & Atividades outdoor \\
\hline 7 & Treino com o peso corporal & Treino com o peso corporal & Exercício como medicina & Treino de saúde/bem-estar & Equipas multidisciplinares ${ }^{\mathrm{a}}$ \\
\hline 8 & Treino de saúde/bem-estar & Treino funcional & $\begin{array}{l}\text { Treino de força com pesos } \\
\text { livres }\end{array}$ & Empregar PF certificados & Fitness e dieta ${ }^{a}$ \\
\hline 9 & Treino funcional & Tecnologia wearable & Exercício para idosos & Exercício para idosos & Novos nichos de mercado ${ }^{a}$ \\
\hline 10 & Tecnologia wearable & Treino de saúde/bem-estar & PT & Licenças (títulos) para PF & Exercício para idosos \\
\hline 11 & PT para pequenos grupos & Medição de resultados & Treino de saúde/bem-estar & PT para pequenos grupos & Licenças (títulos) para PF \\
\hline 12 & HIIT & Exercício como medicina & Aplicações exercício & $\begin{array}{l}\text { Integração clínica com medicina } \\
\text { desportiva/fitness }\end{array}$ & HIIT \\
\hline 13 & $\begin{array}{l}\text { Treino de força com pesos } \\
\text { livres }\end{array}$ & Exercício para idosos & Empregar PF certificados & Treino em circuito & Apps exercício \\
\hline 14 & Exercício como medicina & Fitness pré e pós-parto & Treino funcional & Aulas pós-reabilitação & Medição de resultados \\
\hline 15 & Treino online & PT & Yoga & Exercício para crianças & Treino online \\
\hline 16 & Exercício para idosos & Treino do core & Exercício para perda de peso & Ginásios tipo boutique & Treino com o peso corporal \\
\hline 17 & Medição de resultados & PT para pequenos grupos & Aulas de grupo & Treino de força com pesos livres & Aulas pós-reabilitação \\
\hline 18 & Treino em circuito & Treino em circuito & Medicina como estilo de vida & Aulas de grupo & $\begin{array}{l}\text { Prevenção de lesões, } \\
\text { reabilitação funcional }^{\mathrm{a}}\end{array}$ \\
\hline 19 & $\begin{array}{l}\text { Integração clínica com } \\
\text { medicina desportiva/fitness }\end{array}$ & $\begin{array}{l}\text { Treino de força com pesos } \\
\text { livres }\end{array}$ & Licenças (títulos) para PF & Tecnologia wearable & $\begin{array}{l}\text { Treino de força com pesos } \\
\text { livres }\end{array}$ \\
\hline 20 & Treino do core & $\begin{array}{l}\text { Programas de saúde e bem- } \\
\text { estar no local de trabalho }\end{array}$ & Medição de resultados & Treino do core & Aulas de grupo \\
\hline
\end{tabular}

a: Tendência acrescentada pelos experts do país; Apps exercício: Aplicações de exercício para smartphones; HIIT: Treino intervalado de alta intensidade; PF:

Profissionais de fitness; PT: Treino personalizado; Treino online: Acompanhamento de treino online.

Correspondence to: Liliana Ricardo Ramos

Dirección Postal: Av.Dr.Mário Soares, nº110, 2040-413 Rio Maior, Portugal

Email: lilianaramos@esdrm.ipsantarem.pt

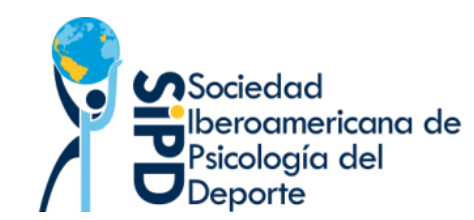


Tabela 4 - Tendências do fitness para 2021, em Portugal, dos profissionais/estudantes do setor do fitness e saúde e dos praticantes de fitness: caracterização e comparação.

\begin{tabular}{|c|c|c|c|}
\hline & $\begin{array}{l}\text { Tendências } \\
\text { Profissionais/ } \\
\text { Estudantes } \\
\text { M } \pm D P\end{array}$ & 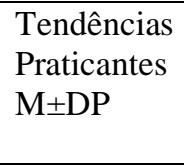 & Teste-T \\
\hline Acompanhamento de treino online & $7.56 \pm 2.03$ & $7.13 \pm 2.27$ & .09 \\
\hline Aparelhos de mobilidade/miofasciais & $6.53 \pm 2.28$ & $7.00 \pm 2.34$ & .09 \\
\hline Aplicações de exercício para smartphones & $7.22 \pm 2.35$ & $7.32 \pm 2.22$ & .75 \\
\hline Atividades outdoor & $8.10 \pm 1.84$ & $8.24 \pm 1.88$ & .56 \\
\hline Aulas de treino militar (boot camp) & $6.08 \pm 2.32$ & $6.15 \pm 2.51$ & .81 \\
\hline Aulas de grupo & $7.27 \pm 2.27$ & $7.29 \pm 2.60$ & .92 \\
\hline Aulas pós-reabilitação & $6.83 \pm 2.31$ & $7.25 \pm 2.33$ & .14 \\
\hline Boxe, kickboxing, ou atividades relacionadas $\mathrm{c} /$ artes marciais & $5.83 \pm 2.34$ & $6.18 \pm 2.32$ & .23 \\
\hline Clubes de caminhadas/corrida/ciclismo & $6.64 \pm 2.24$ & $6.86 \pm 2.19$ & .42 \\
\hline Crosstraining & $7.11 \pm 2.04$ & $6.92 \pm 2.37$ & .46 \\
\hline Desenvolvimento da juventude a longo prazo (desenvolvimento atlético) & $7.01 \pm 2.20$ & $7.28 \pm 2.25$ & .32 \\
\hline Empregar profissionais de fitness certificados & $8.59 \pm 2.05$ & $8.59 \pm 2.09$ & .98 \\
\hline Estilo de vida saudável e mudança comportamental & $8.14 \pm 1.82$ & $8.34 \pm 1.73$ & .37 \\
\hline Exercícios baseados na dança & $5.79 \pm 2.39$ & $6.93 \pm 2.25$ & $.00 *$ \\
\hline Exercício como medicina & $7.65 \pm 2.14$ & $7.74 \pm 2.19$ & .74 \\
\hline Exercício para crianças & $7.15 \pm 2.25$ & $7.33 \pm 2.02$ & .52 \\
\hline Exercício para idosos & $7.45 \pm 2.11$ & $7.66 \pm 2.28$ & .44 \\
\hline Exercício para perda de peso & $8.18 \pm 1.82$ & $8.43 \pm 1.86$ & .29 \\
\hline Fitness pré e pós-parto & $6.95 \pm 2.10$ & $7.62 \pm 2.20$ & $.01 *$ \\
\hline Ginásios tipo boutique & $6.04 \pm 2.47$ & $5.98 \pm 2.61$ & .84 \\
\hline Ginásios/health clubs low cost (baixo custo) & $6.67 \pm 2.40$ & $6.79 \pm 2.29$ & 69 \\
\hline Hidroginástica & $5.80 \pm 2.52$ & $6.24 \pm 2.17$ & .15 \\
\hline Integração clínica com medicina desportiva/fitness & $7.33 \pm 2.07$ & $7.33 \pm 2.14$ & .99 \\
\hline Licenças (títulos) para profissionais de fitness & $8.72 \pm 1.84$ & $8.40 \pm 2.13$ & .17 \\
\hline Medição de resultados & $7.42 \pm 2.13$ & $7.78 \pm 1.90$ & .16 \\
\hline Movimento corpo e mente (body\&mind) & $7.12 \pm 2.20$ & $7.32 \pm 2.41$ & .47 \\
\hline Pilates & $7.14 \pm 2.21$ & $7.29 \pm 2.24$ & .55 \\
\hline Programas de incentivo ao trabalhador & $6.71 \pm 2.25$ & $7.18 \pm 2.43$ & .10 \\
\hline Programas de saúde e bem-estar no local de trabalho & $6.88 \pm 2.21$ & $7.40 \pm 2.40$ & .06 \\
\hline Tecnologia wearable & $7.85 \pm 1.99$ & $7.86 \pm 2.08$ & .96 \\
\hline Treino com electroestimulação & $5.15 \pm 2.39$ & $5.75 \pm 2.49$ & $.04 *$ \\
\hline Treino com o peso corporal & $8.08 \pm 1.84$ & $7.93 \pm 2.15$ & .52 \\
\hline Treino de força com pesos livres & $7.72 \pm 1.91$ & $7.41 \pm 2.21$ & .20 \\
\hline Treino de saúde/bem-estar & $7.99 \pm 1.87$ & $7.81 \pm 2.03$ & .45 \\
\hline Treino do core & $7.27 \pm 2.07$ & $7.59 \pm 2.23$ & .21 \\
\hline Treino em circuito & $7.37 \pm 1.98$ & $7.42 \pm 2.22$ & .84 \\
\hline Treino funcional & $7.90 \pm 1.92$ & $7.88 \pm 2.17$ & .94 \\
\hline Treino intervalado de alta intensidade (HIIT) & $7.74 \pm 2.02$ & $8.09 \pm 2.14$ & .16 \\
\hline Treino personalizado $(\mathrm{PT})$ & $8.58 \pm 1.54$ & $7.60 \pm 2.20$ & $.00 *$ \\
\hline Treino personalizado para pequenos grupos (small group PT) & $7.79 \pm 1.91$ & $7.49 \pm 2.09$ & .22 \\
\hline Treino virtual (virtual training) & $6.83 \pm 2.49$ & $6.67 \pm 2.31$ & 60 \\
\hline Yoga & $6.48 \pm 2.47$ & $6.73 \pm 2.41$ & .37 \\
\hline
\end{tabular}

*: $\mathrm{p} \leq 0.05 ; \mathrm{M}:$ média; DP: desvio padrão 


\section{Franco et al.}

Tabela 5 - Tendências do fitness para 2021, em Portugal, no género feminino e masculino: caracterização e comparação.

\begin{tabular}{|c|c|c|c|}
\hline & $\begin{array}{l}\text { Género } \\
\text { Feminino } \\
M \pm D P\end{array}$ & $\begin{array}{l}\text { Género } \\
\text { Masculino } \\
\text { M } \pm D P\end{array}$ & Teste- $T$ \\
\hline Acompanhamento de treino online & $7.85 \pm 2.04$ & $7.34 \pm 1.99$ & $.03 *$ \\
\hline Aparelhos de mobilidade/miofasciais & $6.93 \pm 2.09$ & $6.23 \pm 2.35$ & $.01 *$ \\
\hline Aplicações de exercício para smartphones & $7.54 \pm 2.34$ & $7.07 \pm 2.30$ & .09 \\
\hline Atividades outdoor & $8.30 \pm 1.74$ & $7.96 \pm 1.90$ & .13 \\
\hline Aulas de treino militar (boot camp) & $6.20 \pm 2.40$ & $5.99 \pm 2.29$ & .44 \\
\hline Aulas de grupo & $7.78 \pm 2.12$ & $6.96 \pm 2.28$ & $.00^{*}$ \\
\hline Aulas pós-reabilitação & $6.97 \pm 2.39$ & $6.78 \pm 2.22$ & .50 \\
\hline Boxe, kickboxing, ou atividades relacionadas com artes marciais & $6.08 \pm 2.29$ & $5.64 \pm 2.36$ & .11 \\
\hline Clubes de caminhadas/corrida/ciclismo & $6.86 \pm 2.34$ & $6.45 \pm 2.18$ & .01 \\
\hline Crosstraining & $7.43 \pm 1.99$ & $6.89 \pm 2.04$ & $.02 *$ \\
\hline Desenvolvimento da juventude a longo prazo (desenvolvimento atlético) & $7.19 \pm 2.05$ & $6.82 \pm 2.30$ & .16 \\
\hline Empregar profissionais de fitness certificados & $8.92 \pm 1.77$ & $8.37 \pm 2.22$ & $.02 *$ \\
\hline Estilo de vida saudável e mudança comportamental & $8.36 \pm 1.82$ & $7.97 \pm 1.80$ & .07 \\
\hline Exercícios baseados na dança & $6.51 \pm 2.36$ & $5.30 \pm 2.30$ & $.00^{*}$ \\
\hline Exercício como medicina & $7.93 \pm 2.08$ & $7.42 \pm 2.17$ & $.04 *$ \\
\hline Exercício para crianças & $7.28 \pm 2.46$ & $7.01 \pm 2.10$ & .32 \\
\hline Exercício para idosos & $7.63 \pm 2.18$ & $7.34 \pm 2.08$ & .25 \\
\hline Exercício para perda de peso & $8.43 \pm 1.68$ & $8.03 \pm 1.90$ & .06 \\
\hline Fitness pré e pós-parto & $7.55 \pm 1.93$ & $6.55 \pm 2.12$ & $.00 *$ \\
\hline Ginásios tipo boutique & $6.07 \pm 2.37$ & $5.99 \pm 2.56$ & .80 \\
\hline Ginásios/health clubs low cost (baixo custo) & $7.12 \pm 2.16$ & $6.33 \pm 2.51$ & $.01 *$ \\
\hline Hidroginástica & $6.12 \pm 2.56$ & $5.54 \pm 2.47$ & .06 \\
\hline Integração clínica com medicina desportiva/fitness & $7.53 \pm 2.06$ & $7.14 \pm 2.06$ & .11 \\
\hline Licenças (títulos) para profissionais de fitness & $9.01 \pm 1.55$ & $8.50 \pm 2.02$ & $.02 *$ \\
\hline Medição de resultados & $7.72 \pm 1.91$ & $7.21 \pm 2.26$ & $.04 *$ \\
\hline Movimento corpo e mente (body\&mind) & $7.97 \pm 1.94$ & $6.54 \pm 2.19$ & $.00 *$ \\
\hline Pilates & $7.86 \pm 1.90$ & $6.66 \pm 2.15$ & $.00 *$ \\
\hline Programas de incentivo ao trabalhador & $6.97 \pm 2.21$ & $6.47 \pm 2.26$ & .06 \\
\hline Programas de saúde e bem-estar no local de trabalho & $7.09 \pm 2.22$ & $6.71 \pm 2.20$ & .15 \\
\hline Tecnologia wearable & $8.17 \pm 1.76$ & $7.61 \pm 2.13$ & $.02 *$ \\
\hline Treino com electroestimulação & $5.82 \pm 2.19$ & $4.68 \pm 2.42$ & $.00 *$ \\
\hline Treino com o peso corporal & $8.31 \pm 1.69$ & $7.90 \pm 1.92$ & .06 \\
\hline Treino de força com pesos livres & $7.87 \pm 1.68$ & $7.59 \pm 2.05$ & .21 \\
\hline Treino de saúde/bem-estar & $8.19 \pm 1.71$ & $7.82 \pm 1.98$ & .10 \\
\hline Treino do core & $7.61 \pm 1.88$ & $7.02 \pm 2.15$ & $.02 *$ \\
\hline Treino em circuito & $7.65 \pm 1.75$ & $7.19 \pm 2.11$ & $.04 *$ \\
\hline Treino funcional & $8.05 \pm 1.71$ & $7.77 \pm 2.06$ & .22 \\
\hline Treino intervalado de alta intensidade (HIIT) & $8.03 \pm 1.61$ & $7.54 \pm 2.25$ & $.03 *$ \\
\hline Treino personalizado (PT) & $8.68 \pm 1.36$ & $8.50 \pm 1.65$ & .33 \\
\hline Treino personalizado para pequenos grupos (small group PT) & $7.92 \pm 1.69$ & $7.70 \pm 2.05$ & .32 \\
\hline Treino virtual (virtual training) & $7.20 \pm 2.36$ & $6.59 \pm 2.54$ & $.04 *$ \\
\hline Yoga & $7.25 \pm 2.03$ & $5.94 \pm 2.24$ & $.00 *$ \\
\hline
\end{tabular}

*: p $\leq 0.05$; M: média; DP: desvio padrão 


\section{Fitness em Portugal para 2021}

Tabela 6 - Tendências do fitness para 2021, em Portugal, de quem estava e de quem não estava a exercer funções enquanto PF: caracterização e comparação.

\begin{tabular}{|c|c|c|c|}
\hline & $\begin{array}{l}\text { Exerce funções } \\
\text { enquanto PF } \\
\text { M DDP }\end{array}$ & 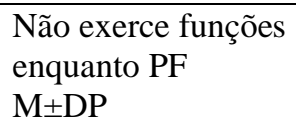 & Teste-T \\
\hline Acompanhamento de treino online & $7.63 \pm 2.08$ & $7.46 \pm 1.99$ & .47 \\
\hline Aparelhos de mobilidade/miofasciais & $6.07 \pm 2.34$ & $6.85 \pm 2.17$ & $.00 *$ \\
\hline Aplicações de exercício para smartphones & $7.07 \pm 2.50$ & $7.41 \pm 2.19$ & .23 \\
\hline Atividades outdoor & $8.29 \pm 1.60$ & $7.95 \pm 1.99$ & .11 \\
\hline Aulas de treino militar (boot camp) & $6.04 \pm 2.14$ & $6.12 \pm 2.48$ & .78 \\
\hline Aulas de grupo & $7.23 \pm 2.27$ & $7.32 \pm 2.25$ & .74 \\
\hline Aulas pós-reabilitação & $6.67 \pm 2.20$ & $7.00 \pm 2.37$ & .22 \\
\hline Boxe, kickboxing, ou atividades relacionadas c/ artes marciais & $5.34 \pm 2.19$ & $6.19 \pm 2.40$ & $.02 *$ \\
\hline Clubes de caminhadas/corrida/ciclismo & $6.49 \pm 2.15$ & $6.70 \pm 2.34$ & .43 \\
\hline Crosstraining & $7.16 \pm 1.97$ & $7.07 \pm 2.10$ & .72 \\
\hline Desenvolvimento da juventude a longo prazo (desen. atlético) & $6.47 \pm 2.28$ & $7.35 \pm 2.08$ & $.01 *$ \\
\hline Empregar profissionais de fitness certificados & $8.56 \pm 2.16$ & $8.61 \pm 2.01$ & .82 \\
\hline Estilo de vida saudável e mudança comportamental & $8.03 \pm 1.74$ & $8.20 \pm 1.87$ & .44 \\
\hline Exercícios baseados na dança & $5.55 \pm 2.42$ & $5.96 \pm 2.37$ & .15 \\
\hline Exercício como medicina & $7.76 \pm 2.17$ & $7.53 \pm 2.15$ & .36 \\
\hline Exercício para crianças & $6.90 \pm 2.26$ & $7.28 \pm 2.27$ & .16 \\
\hline Exercício para idosos & $7.37 \pm 2.17$ & $7.52 \pm 2.09$ & .54 \\
\hline Exercício para perda de peso & $8.08 \pm 1.87$ & $8.26 \pm 1.74$ & .40 \\
\hline Fitness pré e pós-parto & $6.92 \pm 2.23$ & $6.96 \pm 2.00$ & .88 \\
\hline Ginásios tipo boutique & $6.10 \pm 2.75$ & $5.99 \pm 2.26$ & .70 \\
\hline Ginásios/health clubs low cost (baixo custo) & $6.44 \pm 2.42$ & $6.78 \pm 2.39$ & .24 \\
\hline Hidroginástica & $5.37 \pm 2.50$ & $6.05 \pm 2.50$ & $.02 *$ \\
\hline Integração clínica com medicina desportiva/fitness & $7.27 \pm 2.21$ & $7.32 \pm 1.97$ & .84 \\
\hline Licenças (títulos) para profissionais de fitness & $8.63 \pm 2.04$ & $8.75 \pm 1.72$ & .62 \\
\hline Medição de resultados & $7.21 \pm 2.29$ & $7.56 \pm 2.02$ & .17 \\
\hline Movimento corpo e mente (body\&mind) & $7.13 \pm 2.21$ & $7.08 \pm 2.21$ & .85 \\
\hline Pilates & $7.32 \pm 2.21$ & $6.99 \pm 2.08$ & .20 \\
\hline Programas de incentivo ao trabalhador & $6.48 \pm 2.36$ & $6.81 \pm 2.17$ & .21 \\
\hline Programas de saúde e bem-estar no local de trabalho & $6.63 \pm 2.20$ & $7.03 \pm 2.21$ & .13 \\
\hline Tecnologia wearable & $7.78 \pm 2.16$ & $7.88 \pm 1.89$ & .65 \\
\hline Treino com electroestimulação & $4.68 \pm 2.41$ & $5.47 \pm 2.34$ & $.01 *$ \\
\hline Treino com o peso corporal & $8.07 \pm 1.89$ & $8.03 \pm 1.81$ & .85 \\
\hline Treino de força com pesos livres & $7.65 \pm 1.92$ & $7.75 \pm 1.92$ & .66 \\
\hline Treino de saúde/bem-estar & $7.85 \pm 2.00$ & $8.04 \pm 1.78$ & .39 \\
\hline Treino do core & $6.93 \pm 2.16$ & $7.50 \pm 1.96$ & $.02 *$ \\
\hline Treino em circuito & $7.11 \pm 2.08$ & $7.58 \pm 1.90$ & $.04 *$ \\
\hline Treino funcional & $7.74 \pm 2.03$ & $7.96 \pm 1.85$ & .32 \\
\hline Treino intervalado de alta intensidade (HIIT) & $7.61 \pm 2.02$ & $7.84 \pm 2.04$ & .35 \\
\hline Treino personalizado $(\mathrm{PT})$ & $8.63 \pm 1.55$ & $8.52 \pm 1.54$ & .56 \\
\hline Treino personalizado para pequenos grupos (small group PT) & $7.91 \pm 1.87$ & $7.68 \pm 1.95$ & .32 \\
\hline Treino virtual (virtual training) & $6.94 \pm 2.57$ & $6.72 \pm 2.42$ & .46 \\
\hline Yoga & $6.38 \pm 2.17$ & $6.51 \pm 2.31$ & .63 \\
\hline
\end{tabular}

*: $\mathrm{p} \leq 0.05 ; \mathrm{M}:$ média; DP: desvio padrão 


\section{Franco et al.}

Tabela 7 - Tendências do fitness para 2021, para Portugal, nos vários títulos profissionais (TEF, DT e sem título): caracterização e comparação.

\begin{tabular}{|c|c|c|c|c|}
\hline & $\begin{array}{l}\text { TEF } \\
\mathrm{M} \pm \mathrm{DP}\end{array}$ & $\begin{array}{l}\text { DT } \\
\mathrm{M} \pm \mathrm{DP}\end{array}$ & $\begin{array}{l}\text { Sem Título } \\
\mathrm{M} \pm \mathrm{DP}\end{array}$ & $A N O V A$ \\
\hline Acompanhamento de treino online & $7.48 \pm 2.06$ & $7.82 \pm 1.91$ & $7.41 \pm 2.07$ & .34 \\
\hline Aparelhos de mobilidade/miofasciais & $6.47 \pm 2.30$ & $5.74 \pm 2.23$ & $6.97 \pm 2.18$ & $.00^{* 3}$ \\
\hline Aplicações de exercício para smartphones & $7.22 \pm 2.36$ & $7.10 \pm 2.51$ & $7.38 \pm 2.22$ & .69 \\
\hline Atividades outdoor & $8.25 \pm 1.81$ & $8.09 \pm 1.43$ & $8.02 \pm 2.06$ & .70 \\
\hline Aulas de treino militar (boot camp) & $6.05 \pm 2.40$ & $5.86 \pm 2.06$ & $6.22 \pm 2.46$ & .55 \\
\hline Aulas de grupo & $7.23 \pm 2.21$ & $7.09 \pm 2.30$ & $7.41 \pm 2.26$ & .58 \\
\hline Aulas pós-reabilitação & $6.59 \pm 2.37$ & $6.78 \pm 2.15$ & $7.04 \pm 2.33$ & .38 \\
\hline Boxe, kickboxing, ou atividades relac. c/ artes marciais & $5.47 \pm 2.56$ & $5.15 \pm 2.02$ & $6.38 \pm 2.27$ & $.00 * 2.3$ \\
\hline Clubes de caminhadas/corrida/ciclismo & $6.64 \pm 2.11$ & $6.04 \pm 2.30$ & $6.91 \pm 2.26$ & $.02 * 3$ \\
\hline Crosstraining & $7.37 \pm 1.98$ & $6.87 \pm 1.87$ & $7.11 \pm 2.16$ & .33 \\
\hline Desenvolvimento da juventude a longo prazo (atlético) & $6.75 \pm 2.42$ & $6.14 \pm 2.14$ & $7.54 \pm 1.97$ & $.00 * 2.3$ \\
\hline Empregar profissionais de fitness certificados & $8.56 \pm 2.29$ & $8.63 \pm 1.80$ & $8.58 \pm 2.22$ & .98 \\
\hline Estilo de vida saudável e mudança comportamental & $8.21 \pm 1.80$ & $7.77 \pm 1.65$ & $8.29 \pm 1.90$ & .12 \\
\hline Exercícios baseados na dança & $5.73 \pm 2.45$ & $5.40 \pm 2.25$ & $6.02 \pm 2.42$ & .017 \\
\hline Exercício como medicina & $7.49 \pm 2.28$ & $7.86 \pm 2.04$ & $7.57 \pm 2.16$ & .53 \\
\hline Exercício para crianças & $7.11 \pm 2.17$ & $6.68 \pm 2.21$ & $7.36 \pm 2.27$ & .09 \\
\hline Exercício para idosos & $7.48 \pm 2.10$ & $7.22 \pm 2.18$ & $7.57 \pm 2.11$ & .50 \\
\hline Exercício para perda de peso & $8.18 \pm 1.53$ & $7.91 \pm 2.01$ & $8.34 \pm 1.85$ & .25 \\
\hline Fitness pré e pós-parto & $6.92 \pm 2.21$ & $6.82 \pm 2.18$ & $7.02 \pm 2.01$ & .79 \\
\hline Ginásios tipo boutique & $6.23 \pm 2.70$ & $6.35 \pm 2.54$ & $5.76 \pm 2.30$ & .19 \\
\hline Ginásios/health clubs low cost (baixo custo) & $6.84 \pm 2.23$ & $6.13 \pm 2.44$ & $6.81 \pm 2.44$ & .09 \\
\hline Hidroginástica & $5.64 \pm 2.73$ & $5.32 \pm 2.31$ & $6.06 \pm 2.49$ & .11 \\
\hline Integração clínica com medicina desportiva/fitness & $7.01 \pm 2.40$ & $7.47 \pm 1.80$ & $7.35 \pm 2.03$ & .37 \\
\hline Licenças (títulos) para profissionais de fitness & $8.82 \pm 1.88$ & $8.51 \pm 2.03$ & $8.74 \pm 1.75$ & .56 \\
\hline Medição de resultados & $7.12 \pm 2.40$ & $7.09 \pm 2.06$ & $7.73 \pm 2.01$ & $.04 * 1.2 .3$ \\
\hline Movimento corpo e mente (body\&mind) & $7.41 \pm 2.07$ & $7.10 \pm 2.14$ & $6.95 \pm 2.31$ & .35 \\
\hline Pilates & $7.62 \pm 1.86$ & $7.05 \pm 2.23$ & $6.93 \pm 2.18$ & .08 \\
\hline Programas de incentivo ao trabalhador & $6.40 \pm 2.33$ & $6.51 \pm 2.31$ & $6.89 \pm 2.17$ & .24 \\
\hline Programas de saúde e bem-estar no local de trabalho & $6.68 \pm 2.32$ & $6.46 \pm 2.04$ & $7.17 \pm 2.22$ & .06 \\
\hline Tecnologia wearable & $7.59 \pm 2.17$ & $7.82 \pm 2.07$ & $7.98 \pm 1.88$ & .40 \\
\hline Treino com electroestimulação & $5.10 \pm 2.60$ & $4.55 \pm 2.20$ & $5.47 \pm 2.35$ & $.02 * 3$ \\
\hline Treino com o peso corporal & $8.37 \pm 1.65$ & $7.68 \pm 1.99$ & $8.09 \pm 1.82$ & .07 \\
\hline Treino de força com pesos livres & $7.67 \pm 1.77$ & $7.51 \pm 1.95$ & $7.84 \pm 1.98$ & .48 \\
\hline Treino de saúde/bem-estar & $7.86 \pm 1.83$ & $7.76 \pm 1.95$ & $8.12 \pm 1.86$ & .34 \\
\hline Treino do core & $7.07 \pm 2.08$ & $6.76 \pm 2.17$ & $7.63 \pm 1.93$ & $.00 * 3$ \\
\hline Treino em circuito & $7.47 \pm 1.80$ & $6.83 \pm 2.14$ & $7.63 \pm 1.95$ & $.02 * 3$ \\
\hline Treino funcional & $8.25 \pm 1.67$ & $7.21 \pm 2.11$ & $8.04 \pm 1.87$ & $.00 * 1.3$ \\
\hline Treino intervalado de alta intensidade (HIIT) & $7.86 \pm 1.99$ & $7.38 \pm 2.00$ & $7.87 \pm 2.06$ & .20 \\
\hline Treino personalizado (PT) & $8.67 \pm 1.55$ & $8.54 \pm 1.50$ & $8.53 \pm 1.57$ & .80 \\
\hline Treino personalizado para pequenos grupos & $8.14 \pm 1.76$ & $7.68 \pm 1.92$ & $7.66 \pm 1.97$ & .19 \\
\hline Treino virtual (virtual training) & $7.27 \pm 2.36$ & $6.71 \pm 2.49$ & $6.64 \pm 2.52$ & .19 \\
\hline Yoga & $6.60 \pm 1.98$ & $6.26 \pm 2.20$ & $6.49 \pm 2.40$ & .62 \\
\hline
\end{tabular}

*: p $\leq 0.05$; M: média; DP: desvio padrão; ${ }^{1}$ : Diferenças entre TEF e DT; ${ }^{2}$ : Diferenças entre TEF e sem título; ${ }^{3}$ : Diferenças entre DT e sem título 


\section{Fitness em Portugal para 2021}

A $6 .^{a}$ tendência identificada prendeu-se com a realização de atividades no exterior (outdoor) e pode estar relacionada com o facto de muitas pessoas terem começado a treinar no exterior durante a pandemia resultante da doença COVID-19 e se sentirem mais seguras nesse ambiente, acrescendo o clima favorável do país. $\mathrm{O}$ treino com o peso corporal $\left(7 .^{\circ}\right)$ e o treino funcional $\left(9 .^{\circ}\right)$ eram atividades já bastante praticadas nos ginásios/health clubs nos últimos anos e o facto de poderem ser realizadas sem qualquer material, evitando a necessidade da sua desinfeção, pode ter influenciado serem consideradas uma tendência, mais uma vez relacionadas com as restrições impostas pela pandemia COVID-19, o fecho dos ginásios e o facto de os clientes de atividades de fitness terem começado a realizar mais exercício em casa.

A $10{ }^{a}$ tendência identificada tem a ver com a tecnologia wearable (dispositivos tecnológicos vestíveis), sendo que nos últimos anos se assistiu a uma proliferação deste tipo de equipamentos e do seu uso, que pode ter sido potenciado pelo facto de estes serem agora muito mais acessíveis economicamente e permitirem um acompanhamento não só do treino (com contagem da frequência cardíaca, estimação de calorias despendidas, obtenção de metas, etc.) mas também da atividade física diária (como a contagem do número de passos, distâncias percorridas, velocidades, etc.) e darem de certa forma um feedback e acompanhamento ao praticante, para além da possibilidade de partilha com os PT e outros praticantes.

Confrontando os resultados das tendências do fitness dos profissionais/estudantes do setor do fitness de Portugal com os resultados obtidos mundialmente, na Europa e em Espanha (tabela 3) pode verificar-se que do top 20 das tendências identificadas em Portugal, 15 são as mesmas em relação às mundiais (Thompson, 2020), e também 15 são coincidentes com as europeias (Kercher et al., 2020) apesar de não serem as mesmas 15 coincidentes com ambas as regiões. No que se refere a Espanha (Veiga, Valcarce-Torrete \& Cámara, 2021), 14 tendências são coincidentes, sendo que 6 se diferenciam. Apesar desta similaridade, o lugar que as tendências ocupam no top 20 são bastante diferentes. As duas principais tendências em Portugal, nomeadamente licenças (títulos) para profissionais de fitness e empregar profissionais de fitness certificados aparecem apenas em $19 .^{\circ}$ e $13 .^{\circ}$ lugar das tendências mundiais, apesar de na Europa subirem bastantes posições, uma vez que aparecem em $9 .^{\circ}$ e $8 .^{\circ}$ lugar nas tendências europeias e em $11 .^{\circ}$ e $2 .^{\circ}$ lugar em Espanha, revelando uma elevada preocupação na Europa na valorização das qualificações e regulamentação acerca dos profissionais de fitness. A tendência empregar profissionais de fitness certificados costumava encontrar-se no top 3 a nível mundial, desde 2007 até 2016, tendo vindo a decrescer ligeiramente de lugar desde então (Thompson, 2006, 2007, 2008, 2009, 2010, 2011, 2012, 2013, 2014, 2015, 2016, 2017, $2018,2019,2020)$. O treino personalizado e o exercício para a perda de peso, $3 .^{a}$ e $4 .^{a}$ tendências identificada em Portugal, também são bastante valorizadas no estudo europeu, onde ocupam o $10^{\circ} \mathrm{e}$ 4. ${ }^{\circ}$ lugares, e em Espanha, onde ocupam o $3 .^{\circ}$ e $1 .^{\circ}$ lugar. No estudo das tendências do fitness mundiais o treino personalizado surge apenas em $10 .^{\circ}$ lugar, tendo estado no top 3, apenas em 2008 e 2009. Por outro lado, a tendência do acompanhamento de treino online, $\mathrm{n}^{\circ} 1$ das tendências mundiais, ocupa o $15 .^{\circ}$ lugar em Portugal e Espanha e nas tendências Europeias nem sequer faz parte do top 20. Parece deste modo que a Europa, particularmente Portugal e Espanha, não só valorizam mais o serviço presencial, como também individual e personalizado, comparativamente a nível mundial global. Em geral, as tendências em Portugal, Europa e Espanha ocupam posições mais similares do que as mundiais, parecendo que os mercados de Portugal e Espanha, tendem a acompanhar mais as tendências a nível europeu, do que a nível mundial.

Foram caracterizadas e comparadas as tendências do fitness em Portugal, para 2021, entre os profissionais/estudantes e os praticantes de fitness. Salienta-se que do top 20 das tendências identificadas pelos praticantes apenas duas não fazem parte das 20 principais tendências identificadas pelos profissionais/estudantes, nomeadamente o fitness pré e pós-parto e a promoção da saúde e programas de bem-estar no local de trabalho, o que quer dizer que os praticantes de fitness estão bastante alinhados com os profissionais/estudantes. O top 5 identificado por ambos os grupos é muito similar e 4 tendências são as mesmas, sendo que apenas o treino personalizado se diferencia sendo colocado em $3 .^{\circ}$ lugar pelos profissionais/estudantes e em $15 .^{\circ}$ lugar pelos praticantes. Quando comparado o grupo dos profissionais/estudantes com o dos praticantes, 


\section{Franco et al.}

verificou-se que existem diferenças significativas em 4 das 42 tendências do fitness, nomeadamente nos exercícios baseados na dança, fitness pré e pós-parto e treino com electroestimulação, mais valorizadas pelos praticantes do que pelos profissionais/estudantes, e o treino personalizado, mais valorizado pelo profissionais/estudantes do que pelos praticantes. Pelos resultados obtidos, na generalidade, parece que ambos os grupos valorizam, quase, as mesmas tendências, o que se considera positivo, para que os serviços de fitness vão ao encontro da opinião dos praticantes. Apesar das circunstâncias do momento poderem influenciar a opinião acerca das tendências, como por exemplo o aparecimento da pandemia provocada pela doença COVID-19, é natural que os praticantes tendam a ir ao encontro daquilo que o setor do fitness lhes oferece. Se por um lado os serviços devem ir ao encontro das expetativas/preferências dos consumidores, também os consumidores acabam por seguir as tendências do mercado. Contudo, realça-se que a amostra de praticantes não é representativa da população, particularmente pelo seu tamanho, pelo que os resultados têm de ser encarados conscientes dessa limitação.

A prática de atividade física tende a ser distinta entre géneros (TNS Opinion \& Social, 2018), razão pela qual se procedeu à caracterização e comparação das tendências do fitness em Portugal, para 2021, entre géneros. Verificou-se que existem diferenças significativas em 20 das 42 tendências, sendo que em todas as tendências (com diferenças significativas ou não) as mulheres apresentam valores superiores aos homens. As maiores diferenças significativas entre géneros estão relacionadas com as tendências de aulas de grupo, exercícios baseados na dança, fitness pré e pós-parto, movimento corpo e mente, pilates, treino com electroestimulação e yoga, possivelmente mais apreciadas e praticadas pelo género feminino (Freitas, Separowic, Maltese, Passarelli \& Lopes, 2019; Shiraishi, 2013).

Geralmente as tendências do fitness a nível mundial (Thompson, 2020) ou europeu (Kercher et al., 2020) englobam os dados de diversos intervenientes no setor (instrutores de aulas de grupo, de sala de exercício, treino personalizado, fisiologistas do exercício, proprietários e gestores de ginásios, coordenadores de fitness, estudantes da área do desporto/fitness e profissionais de saúde ligados ao exercício), pelo que, com a caracterização e comparação realizada entre quem exercia funções ou não enquanto profissional de fitness, pretendeu-se perceber se quem efetuava funções no mercado do fitness (TEFs, DTs, gestores e coordenadores de fitness no ativo) tinha uma opinião diferente de quem não estava a exercer (TEFs, DTs, gestores e coordenadores que não estavam no ativo, estudantes ou profissionais de saúde relacionados com o exercício). Das 42 tendências existiram diferenças significativas em 7, sendo que em todas elas os profissionais que atualmente não exercia funções apresentaram valores mais elevados. Estas tendências estavam relacionadas com aparelhos de mobilidade/miofasciais, boxe, kickboxing ou atividades relacionadas com artes marciais, desenvolvimento da juventude a longo prazo, hidroginástica, treino com electroestimulação, treino do core e treino em circuito.

Em Portugal os profissionais que atuam nos ginásios/health clubs de acordo com a Lei n. ${ }^{\circ}$ 39/2012 de 28 de agosto, têm de possuir título para tal, o qual pode ser obtido através de uma licenciatura na área do desporto ou educação física (nível 6 QEQ), para o título de DT ou de TEF, ou através de um curso de especialização tecnológica (CET) em técnico especialista em exercício físico (nível 5 QEQ), para o título de TEF. Para além da valorização pelo Governo, na anterior lei referida, vários são também os autores que valorizam a formação para a atuação dos profissionais de fitness (Stacey, Hopkins, Adamo, Shorr, \& Prud'homme, 2010; Franco, 2020). Neste sentido, foi efetuada a caracterização e a comparação da opinião, acerca das tendências de fitness para Portugal em 2021, de quem tem título para ser profissional de fitness, seja TEF ou seja DT, e, supostamente, a devida formação para tal, e de quem não tem esse título (todos os outros respondentes sem título de TEF ou DT, como por exemplo estudantes, profissionais de saúde ligados ao exercício ou proprietários de ginásio). Das 42 tendências verificaram-se diferenças significativas em 9, nomeadamente: aparelhos de mobilidade/miofasciais; boxe, kickboxing, ou atividades relacionadas c/ artes marciais; clubes de caminhadas/corrida/ciclismo; desenvolvimento da juventude a longo prazo (desenvolvimento atlético); medição de resultados; treino com electroestimulação; treino do core; treino em circuito; treino funcional. Todas estas 9 diferenças ocorreram entre o grupo dos DTs e o grupo sem título, 


\section{Fitness em Portugal para 2021}

3 delas entre o grupo do TEFs e os sem título, e apenas duas entre o grupo dos TEFs e dos DTs (medição de resultados; treino funcional). Com exceção da tendência treino funcional, em todas as outras o grupo sem título tem valores significativamente mais elevados. Parece deste modo que as maiores diferenças se encontram entre quem têm título, seja de TEF ou seja de DT, e quem não tem título, como os estudantes de desporto/fitness, os profissionais de saúde ligados ao exercício e alguns dos proprietários e gestores. Realça-se que os portadores do título de DT são os únicos que podem exercer a função de diretor técnico de um ginásio/health club (figura obrigatória em todas as instalações de fitness) e que normalmente intervêm na escolha dos serviços a apresentar aos clientes.

Segundo o Eurobarómetro para o desporto e atividade física (TNS Opinion \& Social, 2018), Portugal é um dos países da União Europeia com piores níveis de prática desportiva, sendo que, no entanto, Portugal é o segundo país, da União Europeia, com maior percentagem de praticantes em ginásios/health clubs (considerando a população com 15 ou mais anos de idade), e estes locais são os segundos mais utilizados pelos portugueses na prática de desporto e atividade física. Este facto realça a importância do setor do fitness em Portugal na prática desportiva dos portugueses. Deste modo, é necessário continuar a contribuir para o desenvolvimento do setor do fitness, podendo o conhecimento acerca das tendências do mesmo concorrer para tal, de modo a que estas ganhem dinâmica e possam criar impacto social a longo prazo, nomeadamente nas atitudes, valores e comportamentos da sociedade (ClubIntel, 2018), para que os níveis de prática desportiva venham a aumentar, promovendo assim a qualidade de vida dos cidadãos.

Pretende-se, no futuro, continuar anualmente com a realização deste estudo para que, tal como nas tendências anuais do ACSM, se possa fornecer informação ao mercado do fitness de Portugal, contribuindo para o seu crescimento. É intenção dos autores aumentar a amostra de profissionais/estudantes do setor do fitness e saúde e, particularmente, dos praticantes de fitness, para que os resultados possam ser encarados como mais representativos das duas populações.
O presente estudo pretendeu aumentar o conhecimento acerca de quais as tendências do fitness em Portugal para o ano de 2021, sendo que esta informação pode ser útil para que as organizações e profissionais que fornecem serviços de fitness possam ajustar a sua oferta.

Numa época difícil como a que se tem vivido, desde a pandemia provocada pela doença COVID-19, que tem ameaçado muitos dos negócios e empregos no fitness, o conhecimento acerca das tendências para o setor pode ser uma contribuição importante para que este se possa ajustar e recuperar rapidamente.

Este estudo permitiu também perceber que, apesar de existir uma propensão para Portugal seguir as tendências, seja a nível mundial, seja, principalmente, a nível europeu, Portugal tem as suas especificidades em termos de tendências em termos de top, nomeadamente "Empregar PF certificados", "Licenças (títulos) para PF" e "Estilo de Vida Saudável e mudança comportamental". Podem as instituições assim como os profissionais do setor português, levar estas tendências em consideração aquando da escolha dos serviços. Existem especificidades de cada país, em termos geográficos e culturais, que devem ser levadas em consideração (ClubIntel, 2018; Kercher et al., 2020), sendo importante o conhecimento das tendências para o fitness país a país. Por outro lado, o presente estudo permitiu perceber que existem certas variáveis relacionadas com as características dos sujeitos que podem levar a opiniões distintas acerca de quais as tendências, realçando-se particularmente o género. Deste modo, sugere-se que no futuro, para além de uma análise por país, se possa também efetuar uma análise acerca das tendências para $o$ fitness considerando as características dos respondentes, tal como foi efetuado neste estudo.

\section{FINANCIAMENTO}

Fundação para a Ciência e a Tecnologia, I.P., Projeto $\mathrm{N}^{\circ}$ UIDP/04748/2020

\section{AGRADECIMENTOS}

Agradece-se a todas as entidades que divulgaram o presente estudo e que permitiram alargar a amostra de respondentes do mesmo.

\section{REFERENCIAS (APA 7ª EDICION)}

\section{APLICAÇÕES PRÁTICAS}




\section{Franco et al.}

1. AGAP (2018). Barómetro do Fitness 2017. Lisboa: Edições AGAP.

2. AGAP (2019). Barómetro do Fitness 2018. Lisboa: Edições AGAP.

3. AGAP (2020). Barómetro do Fitness 2019. Lisboa: Edições AGAP.

4. Alves, S., Franco, S., Castañer, M., Camerino, O., Rodrigues, J. \& Hileno, R. (2015). El análisis de la Comunicación Paraverbal Cinésica y Proxémica de los Instructores de Fitness Mediante Patrones Temporales (T-patterns). Cuadernos de Psicología Del Deporte, 15(1), 111-122. https://doi.org/10.4321/s157884232015000100011

5. American College of Sports Medicine (2021). ACSM's Guidelines for Exercise Testing and Prescription (11 ${ }^{\text {th }}$ Ed.). Philadelphia: Wolters Kluwer.

6. Antunes, A. C. (2003). Perfil Profissional de Instrutores de Academias de Ginástica e Musculação. $\quad$ EFDeportes, $9(60)$. http://www.efdeportes.com/efd60/perfil.htm

7. Batista, P. M., Graça, A., \& Matos, Z. (2008). Termos e Características Associadas à Competência. Estudo Comparativo de Profissionais do Desporto que Exercem a sua Actividade Profissional em Diferentes Contextos de Prática Desportiva. Revista Portuguesa de Ciências do Desporto, 8(3), 377-395. http://doi.org/10.5628/rpcd.08.03.377

8. Batrakoulis, A. (2019). European survey of fitness trends for 2020. ACSMs Health Fitness Journal, 23(6), 28-35.

9. ClubIntel. (2018). International Fitness Industry Trend Report. What's All the Rage? ClubIntel.

10. Dias, I., Franco, S., Ramos, L., \& Simões, V. (2020). Desenvolvimento e Validação do Sistema de Observação do Clima de Aula em Aulas de Grupo de Fitness-Aplicação Piloto em Idosos. Cuadernos de Psicología del Deporte, 20(2), 112127. https://doi.org/10.6018/cpd.382331

11. Ekelund, P. U., Steene-Johannessen, J., Brown, W.J., Fagerland, M. W., Owen, N., Powell, K.E., Bauman, A., \& Lee, I-Min. (2016). Does physical activity attenuate, or even eliminate, the detrimental association of sitting time with mortality? A harmonised meta-analysis of data from more than 1 million men and women. The Lancet, 388(10051), 1302-1310. https://doi.org/10.1016/S0140-6736(16)30370-
12. Franco, S. (2020). Profissionais de Fitness: Enquadramentos. Journal of Sports Pedagogy and Research, 6(1), 4-9. https://doi.org/10.47863/KMPG3820

13. Franco S., Rodrigues J. \& Balcells M. C. (2008). Comportamento pedagógico dos instrutores de aulas de grupo de fitness de localizada. Fitness \& Performance Journal, 7(4):251-263. https://doi.org/10.3900/fpj.7.4.251.p

14. Franco, S., Simões, V., Castañer, M., Rodrigues, J. \& Anguera, M. T. (2013). La Conducta de los Instructores de Fitness: Triangulación entre la Percepción de los Practicantes, Auto-percepción de los Instructores y Conducta Observada. Revista de Psicología Del Deporte, 22(2): 321-329. https://doi.org/10.15332/tg.mae.2015.00582

15. Freitas, C. D., Separowic, C. C., Maltese, C. J., Passarelli, G. F. R. R., \& Lopes, S. C. (2019). Análise do perfil dos praticantes do método Pilates solo e estúdio na cidade de São Paulo. Fisioterapia Brasil, $40(4)$. https://portalatlanticaeditora.com.br/index.php/fis ioterapiabrasil/article/view $/ 3063 / \mathrm{html}$

16. Ho, R. (2014). Handbook of univariate and multivariate data analysis with IBM SPSS. New York: CRC Press.

17. IHRSA (2020). The IHRSA Report. Edições IHRSA.

18. INE. (2019). Inquérito Nacional de Saúde Informação trabalhada pelo INE. https://www.ine.pt/xportal/xmain?xpid=INE\&xp gid=ine_destaques $\& D E S T A Q U E S d e s t \_b o u i=41$ 4434213\&DESTAQUESmodo $=2$

19. Kercher, V. M, Feíto, Y., Yates, B. (2020). Regional comparisons: the worldwide survey of fitness trends. ACSMs Health Fitness Journal, 23(6), 41-48. http://doi.org/10.1249/FIT.0000000000000531

20. Lei n. ${ }^{\circ} 39 / 2012$ de 28 de agosto. Diário da República N. ${ }^{\circ} 166-1 .^{\text {a }}$ Série. Assembleia da República.

21. Lloyd, C. (2008). Recruiting for Fitness: Qualifications and the Challenges of an Employerled System. Journal of Education and Work, 21(3), 175-195. doi: http://doi.org/10.1080/13639080802214019

22. Luís, T., Simões, V., Ramos, L., \& Franco, S. (2021) Desenvolvimento, Validação e Aplicação Piloto do Sistema de Observação da Instrução do Instrutor de Fitness em Aulas de Pilates. 


\section{Fitness em Portugal para 2021}

Cuadernos de Psicología del Deporte, 21(1), 225241. https://doi.org/10.6018/cpd.382381

23. Marquez, D. X., Aguiñana, S., Vásquez, P. M., Conroy, D. E., Erickson, K. I., Hillman, C., Stillman, C. M., Ballardm, R. M., Sheppard, B. B., Petruzzello, S. J., King, A. C., \& Powell, K. E. (2020). A systematic review of physical activity and quality of life and well-being. Translational Behavioral Medicine, 10(5), 1098-1109. https://doi.org/10.1093/tbm/ibz198

24. Pestana, M., \& Gageiro, M. (2014). Análise de dados em ciências sociais: a complementaridade do SPSS (6 $6^{a}$ edição). Lisboa: Sílabo.

25. Ramos, L., Esteves, D., Vieira, I., Franco, S. \& Simões, V. (2021) Job Satisfaction of Fitness Professionals in Portugal: A Comparative Study of Gender, Age, Professional Experience, Professional Title, and Academic Qualifications. Frontiers in Psychology, 11(Art 621526), 1-8. https://doi.org/10.3389/fpsyg.2020.621526

26. Ramos, L., Oliveira., R., Carvalhinho, L. \& Franco, S. (2015). Competências e Formação dos Técnicos de Exercício Físico: Opinião dos Diretores Técnicos de Ginásio. Revista da UIIPS, 3(3), 182-194. https://revistas.rcaap.pt/uiips/article/view/14390/ 10776

27. Shiraishi, J. C. (2013). Perfil dos Praticantes de Ioga em um Ambiente Universitário. Revista Ciência em Extensão, 9(3), 53-60. https://core.ac.uk/download/pdf/300078927.pdf

28. Siddiqui, N., Nessa, A., \& Hossain, M. (2010). Regular physical exercise: way to healthy life. Mymensingh Medical Journal, 19(1), 154-158. https://www.banglajol.info/index.php/MMJ/articl e/view/4472

29. Stacey, D., Hopkins, M., Adamo, K. B., Shorr, R., \& Prud'homme, D. (2010). Knowledge translation to fitness trainers: A systematic review. Implementation Science, 5(1), 28. https://doi.org/10.1186/1748-5908-5-28

30. Thompson, W. R. (2006). Worldwide survey reveals fitness trends for 2007. ACSMs Health Fitness Journal, 10(6), 8-14. http://doi.org/10.1249/01.FIT.0000252519.52241 .39

31. Thompson, W. R. (2007). Worldwide survey reveals fitness trends for 2008. ACSMs Health Fitness Journal, 11(6), 7-13.
http://doi.org/10.1249/01.FIT.0000298449.25061 a8

32. Thompson, W. R. (2008). Worldwide survey reveals fitness trends for 2009. ACSMs Health Fitness Journal, 12(6), 7-14. http://doi.org/10.1249/01.FIT.0000312432.13689 .a4

33. Thompson, W. R. (2009). Worldwide survey reveals fitness trends for 2010. ACSMs Health Fitness Journal, 13(6), 9-16. https://doi.org/10.1249/fit.0b013e3181bcd89b

34. Thompson, W. R. (2010). Worldwide survey reveals fitness trends for 2011. ACSMs Health Fitness Journal, 14(6), 8-17. https://doi.org/10.1249/FIT.0b013e3181f96ce6

35. Thompson, W. R. (2011). Worldwide survey reveals fitness trends for 2012. ACSMs Health Fitness Journal, 15(6), 9-18. http://doi.org/10.1249/FIT.0b013e3181f96ce6

36. Thompson, W. R. (2012). Worldwide survey reveals fitness trends for 2013. ACSMs Health Fitness Journal, 6(6), 8-17. http://doi.org/10.1249/FIT.0b013e31823373cb

37. Thompson, W. R. (2013). Now trending: worldwide survey of fitness trends for 2014. ACSMs Health Fitness Journal, 17(6), 10-20. http://doi.org/10.1249/01.FIT.0000422568.47859 .35

38. Thompson, W. R. (2014). Worldwide survey of fitness trends for 2015: what's driving the market. ACSMs Health Fitness Journal, 18(6), 8-17. http://doi.org/

39. Thompson, W. R. (2015). Worldwide survey of fitness trends for 2016: 10th anniversary edition ACSMs Health Fitness Journal, 19(6), 9-18. http://doi.org/10.1249/FIT.0000000000000164

40. Thompson, W. R. (2016). Worldwide survey of fitness trends for 2017. ACSMs Health Fitness Journal, 20(6), 8-17. http://doi.org/10.1249/FIT.0000000000000252

41. Thompson, W. R. (2017). Worldwide survey of fitness trends for 2018: the CREP edition. ACSMs Health Fitness Journal, 21(6), 10-19. http://doi.org/10.1249/FIT.0000000000000341

42. Thompson, W. R. (2018). Worldwide survey of fitness trends for 2019. ACSMs Health Fitness Journal, 22(6), 10-17. http://doi.org/10.1249/FIT.0000000000000438

43. Thompson, W. R. (2019). Worldwide survey of fitness trends for 2020. ACSMs Health Fitness 


\section{Franco et al.}

Journal, 23(6), 10-18. http://doi.org/10.1249/FIT.0000000000000526

44. Thompson, W. R. (2020). Worldwide survey of fitness trends for 2021. ACSMs Health Fitness Journal, 25(1), 10-9. http://doi.org/10.1249/FIT.0000000000000631

45. TNS Opinion \& Social (2018) Special Eurobarometer 472 - Sport and physical activity. https://ec.europa.eu/sport/news/2018/neweurobarometer-sport-and-physical-activity_en (acesso a 05/10/2020).

46. Veiga, O. L., Valcarce-Torrente, M., Cámara, M. Á. (2021). National Survey of Fitness Trends in Spain for 2021. Retos, 39, 780-789. 